\title{
The Availability of Quality Health Service Dimensions in Government Hospitals in Sudan (A Case Study of Teaching Hospitals in Sudan)
}

\author{
Mohammednour Eltahir Ahmed ${ }^{1} \&$ Ahmed Osman Ibrahim $^{1}$ \\ 1 Department of Business Administration, Faculty of Applied Studies and Community Service-Imam \\ Abdulrahman Bin Faisal University (Dammam formerly), Saudi Arabia Kingdom \\ Correspondence: Mohammednour Eltahir Ahmed, Department of Business Administration, Faculty of Applied \\ Studies and Community Service-Imam Abdulrahman Bin Faisal University (Dammam formerly), Saudi Arabia \\ Kingdom. E-mail: mnour2626@gmail.com
}

Received: April 11, 2017

doi:10.5539/ijbm.v12n6p62
Accepted: May 12, 2017

Online Published: May 17, 2017

URL: https://doi.org/10.5539/ijbm.v12n6p62

\begin{abstract}
This study aimed to identify the levels of quality of health services in government hospitals in Sudan. It also aimed to examine the availability of the dimensions of health services quality, which included tangibles, reliability, responsiveness, confidence and empathy. It has been conducted in the grand didactic hospitals in Khartoum state, Sudan; namely Khartoum, Bahri and Omdurman. The sample of this study included patients and customers who are supposed to benefit from the service under study. The respondents are exposed to a questionnaire of (22) statements to measure the dimensions of the availability of quality in the health service. The findings of the study showed that the patients and customers demonstrated a high level of awareness towards the presence and quality of dimensions of health services provided by government hospitals. It is also revealed that the five health dimensions of quality are not available in government hospitals and their applications are not the concern of the hospital managements.
\end{abstract}

Keywords: quality of health services, government hospitals, teaching hospitals

\section{Introduction}

Unlike other services, the health service and its dimensions have received a considerable attention lately due to its connection with health and human life. This attention was crystallized vigorously as the researchers and interests began to probe the quality of health service and its dimensions that serve as indicators to measure the levels of its quality. Therefore, that the researchers have such considerable concern to improve the quality of health services in different health institutions, particularly in government hospitals. It is also to raise awareness of correct practices to offer better services and acquire the satisfaction of patients and customers, achieve the goals and general policies and finally set up plans for development. To conclude, the study investigated the problems that encountered the health service and its quality in government hospitals in Sudan.

\subsection{The Statement of the Problem}

Measuring the dimensions of quality of any service is one of the vital factors that boost the quality of service-providers (organizations). However, there is no unanimous agreement on determining the quality of services' tools and its related variables, specifically in the field of health sector because of the several schools that defined the concept of quality. The need for establishing government hospitals and dealing with the quality has emerged due to the services provided to the customers, especially allowing the private sector to invest in the provision of health services. The managements of government hospitals in Sudan are faced with several challenges and queries when they offer services to patients and customers. These queries formulated the problem of this study-:

1- What are the factors and variables that affect the dimensions of quality from patients and customers' viewpoints?

2- How can the dimensions of quality be measured from patients and customers' viewpoints?

3- What is the role of the variance of quality dimensions in signifying its importance in relation to patients and customers? 
4- Do the applications of service quality and its concepts lead to patients and customers' satisfaction?

\subsection{The Significance of the Study}

The study is thought to be significant due to the following:

1- Recognizing the opinions and attitudes of patients and customers towards the quality of health services in government hospitals.

2- Identifying the patients and customers' awareness about the dimensions of health service quality in government hospitals.

3- Identifying the patients' expectations for the levels of health service quality.

4- Improving and developing the quality of health services in government hospitals.

\subsection{Hypotheses of the Study}

The study attempts to test the following hypothesis:

1-The first main hypothesis:

The patients and customers in government hospitals in Sudan are aware of the dimensions of the health service quality.

2-The second main hypothesis:

The dimensions of service quality are available in government hospitals in Sudan through tangibles, reliability, responsiveness, confidence and empathy according to the variables of patients and customers.

a-The first sub-hypothesis:

The tangible dimension of the level of health service quality is available in government hospitals.

b-The second sub-hypothesis:

The reliability dimension of the level of health service quality is available in government hospitals.

c-Sub-third sub-hypothesis:

The responsiveness dimension of the level of health service quality is available in government hospitals.

d-The fourth sub-hypothesis:

The confidence dimension of the level of health service quality is available in government hospitals.

e-The fifth sub-hypothesis:

The Empathy dimension of the level of health service quality is available in government hospitals.

\subsection{Methodology of the Study}

The population of this study includes the patients and customers in three didactic hospitals in Khartoum state: Khartoum, Omdurman and Bahri. A sufficient sample has been chosen to represent all the patients and customers of these three hospitals. The study followed the descriptive approach to handle the question of the study. A questionnaire has been designed to assemble data related to the study from the selected sample. Then the researchers adopted the statistical analysis to test the hypotheses by analyzing the Ratios and frequencies for the distribution of customers and their personal details. In addition to analyzing the data, the researchers used the Mean, Median, standard deviation, T-test, and one-way analysis of variance to test the hypotheses of the study. The study is spatially delimited to Didactic hospitals in Khartoum, Omdurman and Bahri and the targeted populations are Patients and customers in these hospitals. The study was conducted during (2014/2015)

\subsection{The Previous Studies}

Sultan's Study (2013): This study entitled "the dimensions of the quality of health services from the beneficiaries' viewpoint (It was an applied study on a group of private hospitals in Basra governorate". The study aimed to identify and assess the level of health services in private hospitals through assessing the five dimensions: tangibles, reliability and response, safety and empathy. It demonstrated the quality of service in terms of availability of dimensions in some of these hospitals. It also showed the presence of statistical differences in the quality of health services among the private hospitals.

Saif's Study (2013): This study entitled "Impact of Application Quality Service Dimensions on Patients Results Field Study in The Jordanian Primary Health Care Centers". The study aimed at identifying attitudes of diabetic patients at the primary health care centers. It concluded that the health centers applied dimensions of service 
quality at an acceptable level. Furthermore, it showed that the impact of the application of service quality dimensions is reflected in patients' results. Moreover, it showed that there is a need to overcome the obstacles to the application of service quality dimensions.

Diab's Study (2012): This study entitled "Measuring Quality Dimensions of Government Hospitals, Medical Services in Jordan: A Staff and Patients Perspective". The study aimed at measuring the quality of medical service dimensions in (30) government hospitals. It concluded that the application of government hospitals and medical service was available and reflected by those dimensions, however, the perspective workers showed no response. The study finally revealed no differences in the dimensions of quality attributed to any of those variables.

Attawail's Study (2010): This study entitled "Possibility to establish the Dimensions of Quality Health Services, a study in a group selected from Hospitals in Nineveh". It aimed at the possibility of setting up the dimensions of quality of health services in the selected hospitals in the province of Nineveh, since the hospital is an organization that provides integrated health, diagnostic and therapeutic, educational and research services. The hospital is an administrative system that uses growing human and technical, material and financial resources that cope with technical and health advancement. The study showed that there is an increasing demand for the health services caused by the wars and their effects, the increase in population, the increasing rates of road accidents, pollution, industrial accidents and others. However, based on these factors, the hospital staff and administration encountered many challenges to provide distinctive quality of health services. The quality of health services is a very important element in hospital management because it is associated with health as one of the essential aspect human life. Therefore, we should support this human requirement and pay full attention to the possibility of establishing the dimensions of quality health services in our hospitals.

Mansour's Study (2006): This study entitled "the health services provided to inpatients in government hospitals in Irbid - Jordan. Study in geographic services". This study aimed to identify the health services provided by government hospitals to inpatients in Irbid City and the extent of their satisfaction with the aspects of physicians, hotel services, nursing, social status, connection. The study was conducted on 224 patients at three government hospitals in Irbid City. The findings of the study showed two levels of satisfaction of inpatients, one is high and the other is low. The study also signifies a high level of satisfaction on the aspect of nursing staff, which ranked first, followed by social status, connection, physicians and hotel services respectively. The findings further showed that there is a significant statistical difference between the aspects of hotel services and income and the aspects of Physician and marital status against satisfaction. However, there was no significant statistical difference between the satisfaction and other independent variables.

\subsection{Foreign Previous Studies}

Zarei Study (2012): Zarei et al, (2012) study entitled "Service Quality of private hospitals". The Iranian patients' perspective" aimed at recognizing the perception of patients to levels of the dimensions of the medical service quality provided by the private medical sector in Iran. The study reached a high of evaluation by patients for the application of quality of service in which the dimensions have been arranged into (tangibles - response reliability - empathy) - the emphasis on descending order.

Study (Desai, 2012): This study entitled "Patient Satisfaction and service Quality Dimensions". It aimed to identify the levels of application dimensions of quality of services offered in Indian hospitals. The study reached that the patient assessment for the application of the quality dimensions was below the average.

Quader's Study (2009): This study entitled "Manger and patient perceptions of a Quality Outpatient service: Measuring the Gap". It aimed to identify the perception of patients for the levels of Services Quality provided in outpatient dimensions. The study found high levels of patients' evaluation for Quality of services' together with their high levels of satisfaction.

All in all, the previous studies handled the issue of the application of the quality of health service dimensions. These studies disclosed the importance of application and attention in order to provide better health services to patients to achieve the highest levels of satisfaction. This study attempts to inspect the availability of quality of health services and the possibility to apply them in government hospitals in Sudan.

\section{The Review of Literature}

\subsection{Definition of Service}

The lack of an accurate and precise definition of service concept when compared to material goods is one of the insuperable obstacles that encounters service organizations, particularly when effectively planning their marketing strategies in the service sector. However that does not dispute the fact that there are many attempts to 
provide a crystal clear and precise definition of the service contributed to the elaboration of dozens researches and studies carried out by academics and practitioners. The American Society for marketing has defined a service as the activities or the benefits offered for sale and that they relate it to exposure of a particular commodity, (Domoor, 2008). It has also been defined as the action, activity or human behavior or any performance from a party to another, and these activities are considered intangible and do not entail any transfer to the ownership of anything and the service may be linked or not linked to a physical tangible product, (Haddad, 2001). Furthermore, it is defined as any business and performance of an intangible work provided by one party to another without resulting in the ownership of something, (Kotler.1975).

\subsection{The Characteristics of the Service}

The characteristics of the service that most researchers agreed upon are as follows:

a-.Intangible .

b-.Concomitance and combination (connection).

c-.Disparity or contrast.

d-.Inability for storage.

e-Fluctuating demand (Almusa'd: 2003)

\subsection{The Quality of Service}

The quality of service provided to customers represents the pivotal factor at the service organizations that seek success and continuity. To achieve the level of the outstanding performance, the organization needs to pay greater attention to the staff and customers together. For this reason, the quality of services plays an important role in the service product designing and service marketing and accordingly it is essential for both providers and users. Therefore, the awareness of the importance of service in organizations and the role of the application of total quality concept can achieve competitive advantages.

\subsection{Definition of Quality Concept}

Quality is a standard for the degree of actual performance of the service conforming to customers' expectations for service, or is the difference between customer expectations for service and understanding of the actual performance, (Haddad, 2001). Quality meets or exceeds the current and future customers' requirements, (Schroeder, 2007). Crosby defines it as to conform to the requirements or specifications, while Goran defined as appropriate for use, (Kumar \& Suresh, 2008).

American Society for Quality defines it as the qualities and characteristics of the total of the product or the service that reflects their ability to meet the explicit and implicit needs, (Heizer \& Render, 2008). It is also recognized as the degree of purposeful mastery aimed to satisfy the needs of the customers, (Imam, 2003). It has also been defined as the quality of services provided and the perceived expected major determinant of consumer satisfaction or dissatisfaction (Sumaidaie, 1992).

These definitions have focused on the nature of the quality, which is perceived as the judgment and the personal estimation by the customers. In other words, the definitions should be from the customers' point of views. When their perception matched with each other's, then they are expected to be satisfied with the service. However, if the product exceeded expectations, then the services are distinctive.

Therefore, the perceived quality represents the customers' judgment for the service, depending on their total experience to receive the service. Therefore, the customers are involved in the process of producing service and thus affect the quality of their level.

\subsection{The Concept of Health Service Quality}

The first person who adopted the concept of "Health Service" in the field of medicine was a British nurse named Florence Nitfeel who was in charge of supervising health care in police hospitals during the Gurom war. By the addition of simple performance criteria to her job, a noticeable reduction was observed in mortalities in those hospitals (Khasroof, 2008).

On the other hand, the health Service has become the core issues in marketing the Healthcare services. Therefore, this issue gained the concern and attention of hospital administrations, beneficiaries of health care, physicians and funding institutions where these parties concentrate on the issue of quality of the health service so as to achieve its objectives and interests. Therefore, any flaws or defect in the quality of the material healthcare are not acceptable and could lead to psychological and personal detriment. Thus, healthcare practice should be free of any flaws or blemishes (Nusray, 2008). 
Since the year 1990 when the initiative of quality assurance has begun to achieve the ongoing development and implementation to improve service quality, the health sector has received great attention to develop it. These methods of quality assurance can help health program managers determine the essential guidelines and the other requirements to evaluate the actual performance compared with set standards of the performance in order to improve the performance of the programs and their effectiveness. Currently, the quality management helps health managers to apply systemic ways to find out the problems and develop appropriate solutions for them.

Officials of quality management develop, choose, and endorse the criteria or standards to improve the quality of health service effectively. This requires great attention from managers to consider the services for the patients, although the quality of service is the basic right for everyone and should be offered by everyone. The focus on the multiple dimensions of quality can help managers to determine priorities of management effectiveness, professionalism, and efficiency. They must also focus on the different needs of patients through resource allocation, scheduling, identifying individuals who provide the service and choose the best management practices (Brown et.al, 2008).

The health service quality means health services are safer and more accessible and more convincing for those who offer them and more pleasing to the beneficiaries so that it generated in the society positive stance on health care, (Al-Assali, 2006).

Donna Bidian has confirmed that the quality of the health service is the application of science and medical techniques for making the most benefits for public health, without exposing it to the increasing risk, and on this basis, the best balance between risks and benefits determines the level of quality. (Khasrov, 2008)

\subsection{Components (Dimensions) of Quality of Service}

According to Imam, there are three dimensions as seen by Grunrot represented in the technical quality, functional quality and mental impression about the organization. Liatimin pointed out that the quality of the services is the product of three main dimensions of the interaction of a physical quality that relate to the surrounding environment to provide the service and the quality of the organization is a mental impression about the organization and the quality of staff interaction with customers. He also believes that many experts in the field of marketing of services have focused on the identification of service quality dimensions and identified ten dimensions for quality of service, (Imam, 2003). The most important dimensions of quality of service are as follows:

\section{1) Tangibles Aspect}

This aspect refers to the appearance of tangible facilities available to service organizations, equipment, individuals, and dealers with service providers, tools and means of communication between them. The service is often evaluated based on phenotypic or basic accompaniment of service such as tangible facilities (machines, equipment, etc.).

\section{2) Reliability Aspect}

This aspect refers to the ability of the service organization in their implementation of the service that has reliably pledged and at a high degree of correctness and accuracy. Customers are expected to receive accurate service in terms of time commitment and performance just as was agreed upon.

\section{3) Responsiveness Aspect}

This relates to the ability, the desire and willingness of service providers to permanently be in customer service and their ability to serve them when they needed.

\section{4) Assurance Aspect (Confidence and credibility)}

What degree of confidence in the service provider, is s/he trustworthy? What is the credibility of the service provider? Is he committed to what s/he says?

\section{5) Empathy (sympathy) Aspect}

This aspect refers to the ability of the service provider to identify and understand the customers' needs and provide them with care and attention. For instance, s/he needs to know how much time and effort needed by the provider to recognize the customer's needs? How does the service provider understand the customers' feelings and sympathize with their problems? (Aldamoor, 2008) 


\subsection{Empirical Study}

\subsubsection{Procedures of the Study}

A questionnaire of 22 statements was designed based on the quality standards by Barry, (1988) to study the five dimensions of quality: tangibles, reliability, responsiveness, assurance and empathy. The researchers have distributed 750 questionnaires to the study sample in Khartoum, Bahri and Omdurman teaching hospitals. The questionnaire copies have been equally distributed, i.e. 250 questionnaires for each hospital. A total of 586 questionnaires was assembled, i.e. (72.2\%) of the total. This percentage enabled the researchers to conduct the study.

\subsubsection{Validity and Reliability of the Questionnaire}

The questionnaire of the study was sent to the arbitrators to inspect its validity. The feedback of the arbitrators has been received and followed, and then the questionnaire was designed in its final form. The reliability of questionnaire means consistency of results when applied to more than one time. The reliability coefficient values were calculated by Alpha-Cronbach to the scale as per table (2). The correlation coefficient was calculated by Cronbach Alpha as well for each statement as shown in table (3) which shows the results:

Table 1 . Shows reliability of the questionnaire

\begin{tabular}{ll}
\hline Statements & Alpha-Cronbach \\
\hline 22 &, 840 \\
\hline
\end{tabular}

Table 1 shows (Alpha Cronbach) coefficient to confirm of the reliability questionnaire, which equals to (84). This very high value indicates that the instrument has reflected a high degree of reliability and achieved the objectives of the study.

Table 1 shows (see appendixes) that the value of the correlation coefficient and consistency for almost all statements are high and statistically functioned which confirm the questionnaire validity.

Table 2. A Fifth likert scale table and the weighted average

\begin{tabular}{llll}
\hline Response & Weight & The weighted average & Average \\
\hline Strongly agree & 1 & $1-1,79$ & 3 \\
Agree & 2 & $1,80-2,59$ & \\
Undecided & 3 & $2,60-3,39$ & \\
Disagree & 4 & $3,40-4,19$ & \\
Strongly disagree & 5 & $4,20-5$ & \\
\hline
\end{tabular}

Table 2 shows the following:

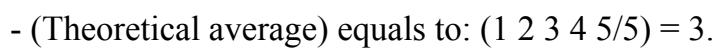

- For example, the average of the first axis (theoretical average), the number of statements multiplied by the average statement.

- Weighted average determines the direction of the opinion for any individual statement based on the average statement, which is calculated from the results of respondents' answers compared with the theoretical average.

\subsubsection{Statistical Processing Methods}

The data of the study has been processed by Statistical Package for Social Sciences (SPSS). The following is statistical methods that have been used:

1. The mean (arithmetic mean indicates how the concentration of data about a certain value and equals the sum of the values divided by its number).

2. Standard deviation (indicates how the dispersion of data from each other and equal to the sum of square deviations values divided by its number).

3. Alpha-Cronbach (an equation used to measure the reliability of the questionnaire).

4. (T-test) for one sample (This test is used to assess the presence of a significant difference to the average community (the theoretical average), which was taken from the mean of the sample (the respondents). 
5. Analysis of variance (P) for one sample to determine the extent to which the quality of health service dimensions.

\subsubsection{The Study Sample Characteristics}

Table 3. Frequency distribution of the personal variables of the study sample

\begin{tabular}{|c|c|c|c|}
\hline Variable & Category & Frequencies & Percentage \\
\hline \multirow{3}{*}{ Type } & Male & 436 & 74.4 \\
\hline & Female & 150 & 25.6 \\
\hline & Total & 586 & $100 \%$ \\
\hline \multirow{7}{*}{ Age } & $20-30$ & 37 & 6.3 \\
\hline & $31-40$ & 148 & 25.3 \\
\hline & $41-50$ & 232 & 39.6 \\
\hline & $51-60$ & 147 & 25.1 \\
\hline & More than 60 & 22 & 3.8 \\
\hline & Total & 586 & $\% 100$ \\
\hline & Educated & 33 & 5.6 \\
\hline \multirow{4}{*}{ Education Level } & Intermediate and less & 142 & 24.2 \\
\hline & Secondary & 248 & 42.3 \\
\hline & Graduate & 143 & 24.4 \\
\hline & Postgraduate & 20 & 3.4 \\
\hline \multirow{5}{*}{ Income level } & Total & 586 & $\% 100$ \\
\hline & Low & 271 & 46.2 \\
\hline & Average & 296 & 50.5 \\
\hline & High & 19 & 3.2 \\
\hline & Total & 586 & $100 \%$ \\
\hline \multirow{3}{*}{ Residence } & Village & 331 & 56.5 \\
\hline & Town & 255 & 43.5 \\
\hline & Total & 586 & $100 \%$ \\
\hline
\end{tabular}

From the table above:

\section{- Type}

The table shows that the majority of the respondents were male (74.4\%), while the female ratio was $25.6 \%$.

\section{- Age}

It is obvious that the majority of respondents were in the age category (41-50) by $39.6 \%$, while the lowest percentage was $3.8 \%$ for those aged (over 60 years).

\section{- Education (Qualification) level}

It is clear that the majority of respondents $(42.3 \%)$ was a secondary school certificate (academic qualification) followed by a Masters $(22.8 \%$,), while the lowest percentage was postgraduate $(15.2 \%)$ and is attributed to the fact that many of the postgraduate qualifications are associated with the institutions in which they work, what is known as health insurance with private hospitals.

\section{- Income level}

It is obvious that the majority of the respondents revealed that they are middle-income, their percentage was $50.5 \%$, and the lowest was of (high income) increased by $3.2 \%$, due to the prevailing economic situation and the rising cost of health services in private hospitals.

\section{- Residence}

Concerning the residence, the majority of respondents was from the rural areas and accounted for $56.5 \%$, while the urban area was $43.5 \%$, due to the lack of medical services in the latter.

\section{Test Hypotheses}

\subsection{The First Main Hypothesis}

Patients and customers in Sudanese government hospitals displayed a full awareness of the dimensions of the 
quality of health service.

Table 4. (T) Analysis for the respondents' awareness of the dimensions of the quality of service

\begin{tabular}{|c|c|c|c|c|c|c|c|c|c|}
\hline No. & Dimension & Statement & T-test & $\mathrm{DF}$ & Sig & $\begin{array}{l}\text { Degree } \\
\text { of Sig }\end{array}$ & Average & SD & Order \\
\hline 1 & & $\begin{array}{l}\text { Government hospitals offer health and } \\
\text { therapeutic services needed by patients. }\end{array}$ & 50.501 & 585 & .000 & $\begin{array}{l}\text { v. } \\
\text { Strong }\end{array}$ & 3.10 & 1.485 & 21 \\
\hline 2 & & $\begin{array}{l}\text { The government hospitals appoint trained } \\
\text { and qualified Medical staffs. }\end{array}$ & 51.999 & 585 & .000 & $\begin{array}{l}\text { v. } \\
\text { Strong }\end{array}$ & 3.19 & 1.487 & 11 \\
\hline 3 & & $\begin{array}{l}\text { Physicians' offices and patients' lounges are } \\
\text { appropriate for the therapeutic services; the } \\
\text { patients expected to receive. }\end{array}$ & 49.800 & 585 & .000 & $\begin{array}{l}\text { v. } \\
\text { Strong }\end{array}$ & 3.13 & 1.524 & 16 \\
\hline 4 & langibles & $\begin{array}{l}\text { Managements of government hospitals } \\
\text { provide the required physical supplies of } \\
\text { devices and medical equipment to offer the } \\
\text { service. }\end{array}$ & 50.206 & 585 & .000 & $\begin{array}{l}\text { v. } \\
\text { Strong }\end{array}$ & 3.13 & 1.509 & 16 \\
\hline 5 & & $\begin{array}{l}\text { The general appearance of government } \\
\text { hospitals Commensurate with the health and } \\
\text { therapeutic services. }\end{array}$ & 48.421 & 585 & .000 & $\begin{array}{l}\text { v. } \\
\text { Strong }\end{array}$ & 3.11 & 1.556 & 19 \\
\hline 6 & & $\begin{array}{l}\text { Government hospitals administrations are } \\
\text { committed to offer therapeutic health } \\
\text { services that customers are expected to find. }\end{array}$ & 52.902 & 585 & .000 & $\begin{array}{l}\text { v. } \\
\text { Strong }\end{array}$ & 3.23 & 1.480 & 10 \\
\hline 7 & & $\begin{array}{l}\text { Government hospitals pay undivided } \\
\text { attention to health service and usually on } \\
\text { specific time and demand. }\end{array}$ & 55.042 & 585 & .000 & $\begin{array}{l}\text { v. } \\
\text { Strong }\end{array}$ & 3.31 & 1.454 & 7 \\
\hline 8 & Credibility & $\begin{array}{l}\text { Government Hospital administrations pay } \\
\text { attention to the exact calculations to get } \\
\text { information from patients, then record and } \\
\text { store them. }\end{array}$ & 50.367 & 585 & .000 & $\begin{array}{l}\text { v. } \\
\text { Strong }\end{array}$ & 3.18 & 1.526 & 12 \\
\hline 9 & & $\begin{array}{l}\text { Government Hospital administrations take } \\
\text { the complaints of the patients into account } \\
\text { seriously. }\end{array}$ & 54.327 & 585 & .000 & $\begin{array}{l}\text { v. } \\
\text { Strong }\end{array}$ & 3.34 & 1.488 & 4 \\
\hline 10 & & $\begin{array}{l}\text { Government Hospital administrations notify } \\
\text { the patients with the proper Health services. }\end{array}$ & 55.095 & 585 & .000 & $\begin{array}{l}\text { v. } \\
\text { Strong }\end{array}$ & 3.35 & 1.472 & 3 \\
\hline 11 & & $\begin{array}{l}\text { The staffs at government hospitals } \\
\text { incessantly offer the assistance requested by } \\
\text { the patients. }\end{array}$ & 53.647 & 585 & .000 & $\begin{array}{l}\text { v. } \\
\text { Strong }\end{array}$ & 3.31 & 1.494 & 7 \\
\hline 12 & Responsiveness & $\begin{array}{l}\text { Patients are expected to receive the } \\
\text { immediate required services from staff at } \\
\text { government hospitals. }\end{array}$ & 54.669 & 585 & .000 & $\begin{array}{l}\text { v. } \\
\text { Strong }\end{array}$ & 3.33 & 1.474 & 5 \\
\hline 13 & & $\begin{array}{l}\text { The staffs at government hospitals respond } \\
\text { positively to patients during their busy } \\
\text { schedule. }\end{array}$ & 55.956 & 585 & .000 & $\begin{array}{l}\text { v. } \\
\text { Strong }\end{array}$ & 3.37 & 1.459 & 1 \\
\hline 14 & & $\begin{array}{l}\text { Patients have confidence in medical Medical } \\
\text { staffs and their assistance in government } \\
\text { hospitals }\end{array}$ & 51.610 & 585 & .000 & $\begin{array}{l}\text { v. } \\
\text { Strong }\end{array}$ & 3.16 & 1.484 & 14 \\
\hline 15 & Confidence & $\begin{array}{l}\text { Patients feel with heartsease to deal with } \\
\text { medical staffs while providing Health } \\
\text { Service }\end{array}$ & 51.774 & 585 & .000 & $\begin{array}{l}\text { v. } \\
\text { Strong }\end{array}$ & 3.17 & 1.482 & 13 \\
\hline 16 & & $\begin{array}{l}\text { The patients develop a sense of interaction } \\
\text { with staffs in government hospitals in terms } \\
\text { of Health needs. }\end{array}$ & 48.011 & 585 & .000 & $\begin{array}{l}\text { v. } \\
\text { Strong }\end{array}$ & 3.10 & 1.563 & 21 \\
\hline 17 & & $\begin{array}{l}\text { The patients feel with the good treatment of } \\
\text { staffs and they realize their medical and } \\
\text { technical capabilities while receiving health }\end{array}$ & 48.447 & 578 & .000 & $\begin{array}{l}\text { v. } \\
\text { Strong }\end{array}$ & 3.12 & 1.551 & 18 \\
\hline
\end{tabular}




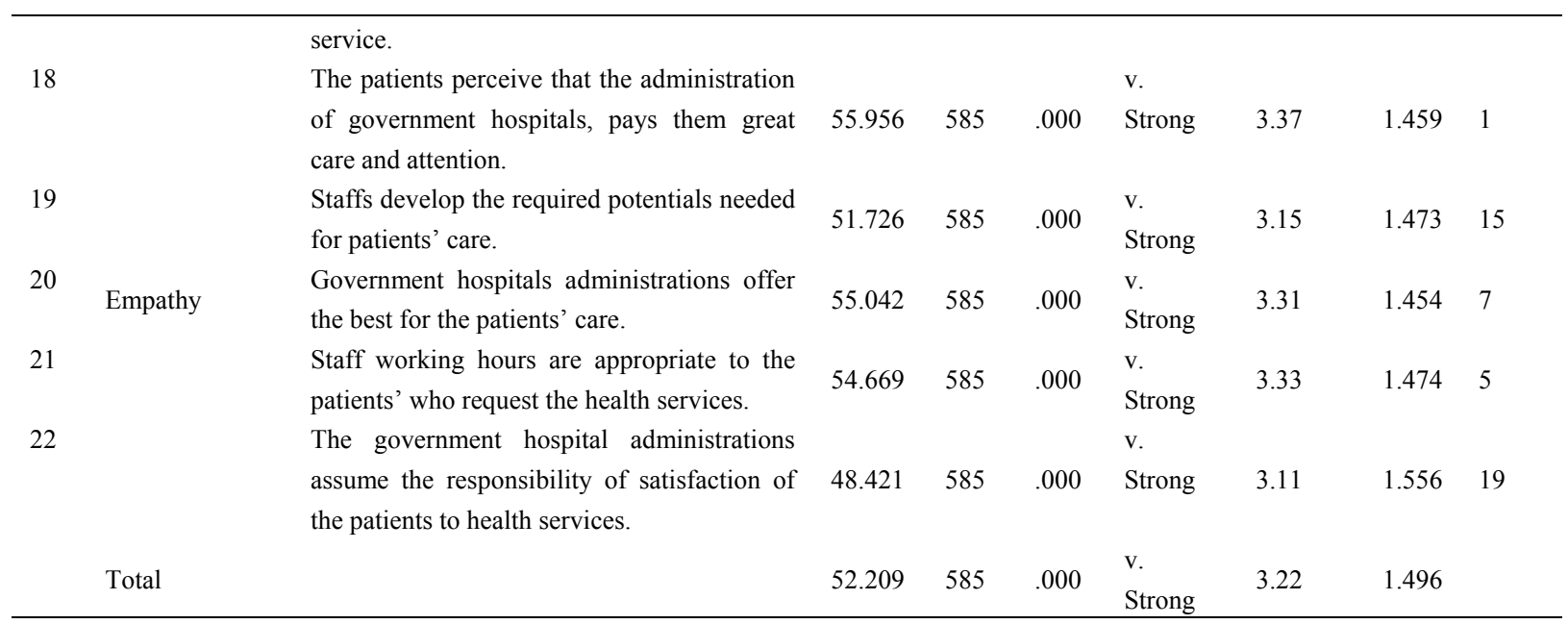

It is noted from the table 4 that the respondents had stressed the importance of the dimensions of quality of health service. This is shown by the means of statements which exceeded (3), the average statement. The standard deviations were lower than (1) and the value of (T-test) was statistically significant for all statements. This can be observed through the prospective values, which were below the level of statistical significance (0.05) for each statement. It is also seen from the table that there were significant differences between the average sample and the average scale in favor of the respondents' differences where the average of the answers respondents (3.22) and where the (T) value was stressed and it reached (52.209). Therefore, the difference was statistically significant against the significance level (0.05) in favor of the respondents. This demonstrates that the respondents' perception of the importance of service quality dimensions in health services. So, the hypothesis "the inpatients and customers in government hospitals in Sudan are aware of the dimensions of the health service quality" is correct and accepted and its negation is rejected.

\subsection{The Second Main Hypothesis}

The dimensions of service quality are available in government hospitals in Sudan through tangibles, reliability, responsiveness, confidence and sympathy according to the variables of patients and customers.

\subsubsection{Sub-First Hypothesis}

The tangible dimension of the level of quality of health service is available in government hospitals.

Table 5. Variance analysis of tangible dimension

\begin{tabular}{lllllll}
\hline Source of variation & & Total & Degree of Freedom & Average & (F) Value & Sig \\
\hline \multirow{4}{*}{ Type } & Between groups & 4.276 & 20 & .214 & 1.126 & .318 \\
& Inside groups & 107.328 & 565 & .190 & & \\
& Total & 111.604 & 585 & & & \\
Age & Between groups & 17.304 & 20 & .865 & .955 & .517 \\
& Inside groups & 512.056 & 565 & .906 & & \\
\multirow{5}{*}{ Education } & Total & 529.360 & 585 & & & \\
& Between groups & 11.190 & 20 & .559 & .652 & .873 \\
\multirow{3}{*}{ Income Level } & Inside groups & 484.744 & 565 & .858 & & \\
& Total & 495.933 & 585 & & & \\
& Between groups & 5.580 & 20 & .279 & .895 & .593 \\
\multirow{3}{*}{ Residence } & Inside groups & 176.052 & 565 & .312 & & \\
& Total & 181.631 & 585 & & & \\
& Between groups & 5.770 & 20 & .289 & 1.179 & .267 \\
\hline
\end{tabular}

Table 5 shows that the $(\mathrm{F})$ values of the dimension of tangibles for measuring the level of quality of health service depended on personal variables. The values were (0.955) (1.126) (0.652) (0.895) and (1.179). The 
significance of the values were (0.318) (0.517) (0.873) (0.593) and (0.267), and all these values were greater than $(0.05)$. This means that the dimension of tangibles of quality of health service is unavailable in Sudanese government hospitals according to personal variables. Therefore the hypothesis:

"The dimensions of service quality are available in government hospital in Sudan through tangibles, reliability, responsiveness, confidence and sympathy according to the variables of patients and customers" is not acceptable. Therefore, the null hypothesis is accepted.

\subsubsection{Sub-Second Hypothesis}

(Health Quality services are available in government hospitals in Sudan based on the dimension of the reliability of the quality of health services).

Table 6. Analysis of variance of reliability dimension

\begin{tabular}{lllllll}
\hline Source of variation & & Total & Degree of Freedom & Average & (F) Value & Sig \\
\hline \multirow{4}{*}{ Type } & Between groups & 3.911 & 16 & .244 & 1.291 & .197 \\
& Inside groups & 107.693 & 569 & .189 & & \\
& Total & 111.604 & 585 & & & \\
Age & Between groups & 20.811 & 16 & 1.301 & 1.455 & .111 \\
& Inside groups & 508.549 & 569 & .894 & & \\
Education & Total & 529.360 & 585 & & & \\
Level & Between groups & 14.748 & 16 & .922 & 1.090 & .361 \\
& Inside groups & 481.186 & 569 & .846 & & \\
Income & Total & 495.933 & 585 & & & \\
Level & Between groups & 4.252 & 16 & .266 & .853 & .625 \\
& Inside groups & 177.379 & 569 & .312 & & \\
Residence & Total & 181.631 & 585 & & & \\
& Between groups & 5.213 & 16 & .326 & 1.335 & .170 \\
& Inside groups & 138.823 & 569 & .244 & & \\
\hline
\end{tabular}

Table 6 shows that the (F) values of the dimension of reliability are analyzed to measure the level of quality of health service depending on personal variables. These values were (1.455) (1.291)) (1.090) (0.853) (1.335), and the values of the significance levels were $(0.197)(.111)(0.361)(0.625)(0.170)$ respectively, and each one is greater than (0.05), which means that this dimension is not available in Sudanese government hospitals. Therefore, this hypothesis "The reliability dimension of the level of health service quality is available in government hospitals" is not available, incorrect and unacceptable and the null hypothesis is accepted.

\subsubsection{Sub-Third Hypothesis}

The responsiveness dimension of the level of quality of health service is available in government hospitals.

Table 7. The variance analysis of responsiveness dimension

\begin{tabular}{lllllll}
\hline Source of variation & & Total & Degree of Freedom & Average & (F) Value & Sig \\
\hline \multirow{4}{*}{ Type } & Between groups & 3.215 & 16 & .201 & 1.055 & .396 \\
& Inside groups & 108.389 & 569 & .190 & & \\
Age & Total & 111.604 & 585 & & & \\
& Between groups & 14.562 & 16 & .910 & 1.006 & .448 \\
Education & Inside groups & 514.798 & 569 & .905 & & \\
Level & Total & 529.360 & 585 & & & \\
& Between groups & 8.239 & 16 & .515 & .601 & .884 \\
Income & Inside groups & 487.695 & 569 & .857 & & \\
Level & Total & 495.933 & 585 & & & \\
& Between groups & 3.147 & 16 & .197 & .627 & .863 \\
Residence & Inside groups & 178.485 & 569 & .314 & & \\
& Total & 181.631 & 585 & & & \\
& Between groups & 4.846 & 16 & .303 & 1.238 & .234 \\
\hline
\end{tabular}


Table 7 shows the $(\mathrm{F})$ value of responsiveness dimension of the quality of health service. The personal variables were (1.006), (1.055)), (0.601), (0.627), and (1.238) while the significance level was (0.396), (0.448), (0.884), $(0.863)$ and $(0.234)$, respectively. Since all of these significance levels were greater than $(0.05)$, which means the responsiveness dimension of the quality of health, service is unavailable in government hospitals in Sudan depending on personal variables. Thus, the hypothesis: "The responsiveness dimension of the level health service quality is available in government hospitals" is incorrect and unacceptable and the null hypothesis is acceptable.

\subsubsection{The Fourth Sub-Hypothesis}

The confidence dimension of the level of quality of health service is available in government hospitals.

Table 8 . The variance analysis of confidence dimension

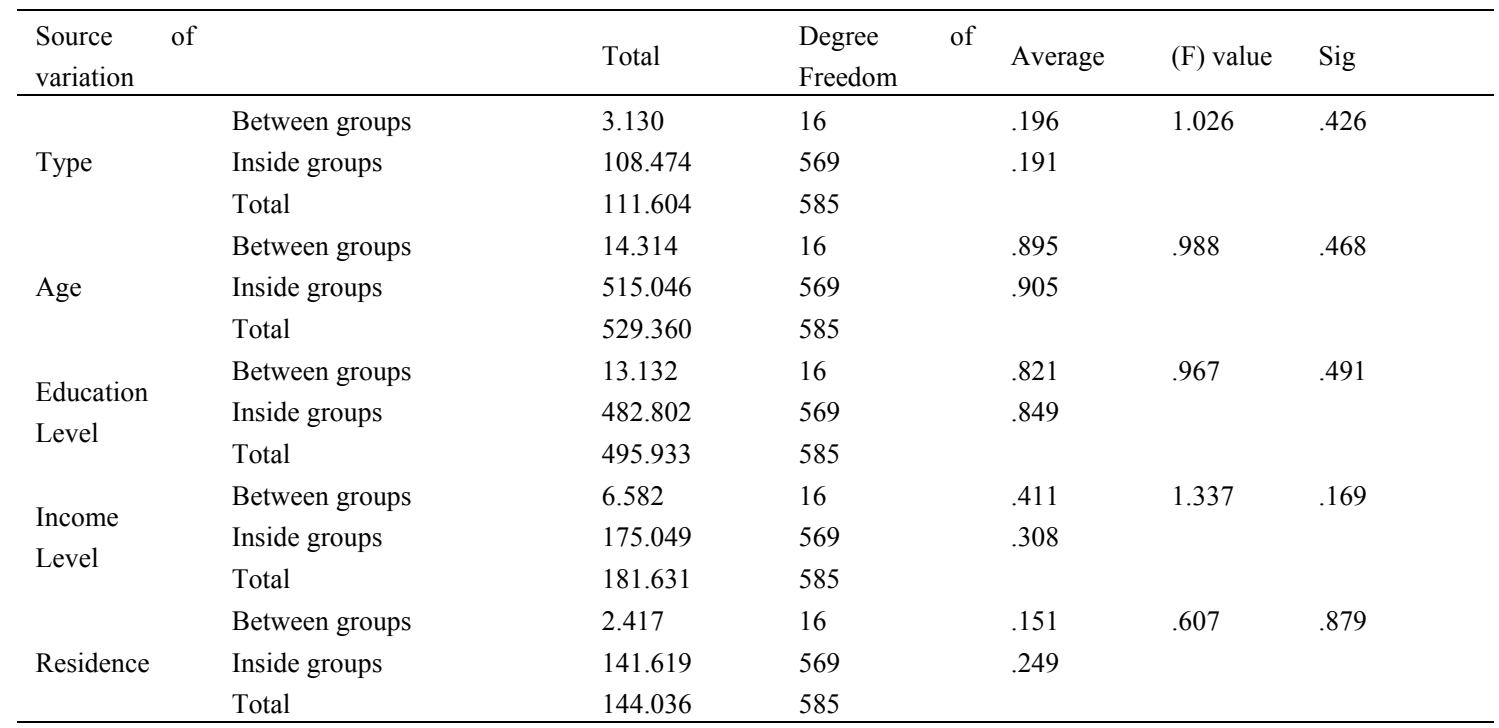

Table 8 shows that the $(\mathrm{F})$ values of the confidence dimension of the quality health service. The values of personal variables were $(0.988),(1.026),(0.967),(1.337)$ and $(0.607)$, and the values of the significance level included $(0.426),(0.468),(0.491),(0.169)$ and $(0.879)$. All these values were greater than $(0.05)$, which indicates that the dimension of the confidence of the quality of health service is unavailable in government hospitals in Sudan, along with personal variables. Therefore, the hypothesis: "The confidence dimension of the level health service quality is available in government hospitals" is incorrect and unacceptable. Thus, the null hypothesis is accepted.

\subsubsection{The Fifth Sub-Hypothesis}

"The Empathy dimension of the level health service quality is available in government hospitals."

Table 9. Variance of sympathy dimension analysis

\begin{tabular}{|c|c|c|c|c|c|c|}
\hline Source of variation & & Total & $\begin{array}{l}\text { Degree of } \\
\text { Freedom }\end{array}$ & Average & (F) Value & Sig \\
\hline \multirow{3}{*}{ Type } & Between groups & 4.298 & 20 & .215 & 1.131 & .312 \\
\hline & Inside groups & 107.307 & 565 & .190 & & \\
\hline & Total & 111.604 & 585 & & & \\
\hline \multirow{3}{*}{ Age } & Between groups & 11.993 & 20 & .600 & .655 & .871 \\
\hline & Inside groups & 517.367 & 565 & .916 & & \\
\hline & Total & 529.360 & 585 & & & \\
\hline \multirow{3}{*}{$\begin{array}{l}\text { Education } \\
\text { Level }\end{array}$} & Between groups & 35.514 & 20 & 1.776 & 2.179 & .002 \\
\hline & Inside groups & 460.419 & 565 & .815 & & \\
\hline & Total & 495.933 & 585 & & & \\
\hline
\end{tabular}




\begin{tabular}{lllllll}
\hline & Between groups & 9.069 & 20 & .453 & 1.485 & .080 \\
Lncome & Inside groups & 172.562 & 565 & .305 & & \\
& Total & 181.631 & 585 & & & .452 \\
Residence & Between groups & 4.956 & 20 & .248 & & 1.007 \\
& Inside groups & 139.080 & 565 & .246 & & \\
\hline
\end{tabular}

Table 9 displays that the (F) values of the Empathy dimension of the quality of health service depending on personality variables. These values were $(0.655),(1.131),(2.179),(1.485)$ and $(1.007)$ while the values of the significance level included (0.312), (0.871), (0.002), (0.080) and $(0.542)$. The total significance is greater than (0.05) except for education level, which was less variable (0.05). This confirms the Empathy dimension is available. This assures that the Empathy dimension in the quality of health service is unavailable government hospitals in Sudan based on personal variables.

Therefore, the hypothesis: "The Empathy dimension of the level health service quality is available in government hospitals." is incorrect and unacceptable. Thus, the null hypothesis is accepted.

\subsection{The Total Result of the Hypothesis}

From the analysis in the tables (6), (7), (8), (9) and (10) the researchers concluded that the hypothesis:

"The dimensions of service quality are available in government hospitals in Sudan through tangibles, reliability, responsiveness, confidence and Empathy, according to the variables of patients and customers" is incorrect and unacceptable. Thus, the null hypothesis is acceptable depending on the personal variables of patients and customers).

\section{Findings and Conclusions}

\subsection{The Study Concluded with the Following}

1- The patients and customers are fully aware of the required levels of health services to be provided by government hospitals in Sudan.

2- Government hospitals do not offer the necessary supplies for the provision of health services.

3- Government hospitals do not employ the qualified medical staff, as they prefer to work in the private health sector.

4- Health services are not accessible in government hospitals in the proper time.

5- The patients and customers develop a sense of insecurity and fear of the lack of the necessary medical staff and medical ingenuity and their assistance when receiving health services in government hospitals.

6- The patients and customers are obliged to do the checkup at the private hospitals, and therefore do not have an option to review but the government hospitals.

\subsection{Recommendations}

1- Government hospitals should be supplied with the necessary devices and equipment.

2- Medical staffs and their assistants should be made available in government hospitals.

3- Appropriate environmental assessment should be considered to attract the Medical staffs to work in government hospitals.

4- Creating patients and customers' confidence to return to government hospitals by adopting previous

5 - Studying the experiences applied in the developed countries, medically and transported properly.

6- Training medical staff and technical assistants up to the highest level to provide proper medical service.

\section{References}

Alasali, M. A. (2006). The reality and the requirements of the development of the health situation. The National Congress for scientific research and cultural development, Damascus, Syria

Aldamoor, H. (2008). Marketing services- Amman Dar Wael for printing and publishing.

Almassed, Z. K. (2003). Marketing Services and its applications. Amman, curriculum House for publishing and distribution. 
Brown, L. D., Franco, L. M., Rafeh, N., \& Hatzell, T. (2008). Quality Assurance of Health Care in Developing Countries. Quality Assurance Project.

Desai, V. (2011). Patient Satisfaction and service Quality Dimensions. Advances in Management Journal, 4(5).

Diab, S. M. (2012). Measure the dimensions of the quality of medical services provided in the Jordanian government hospitals from the patients and staff perspective. The Islamic University Journal of Economics and Management Studies, 20(1).

Haddad, A. (2001). Marketing Banking services. CAIRO, Bayan for printing, publishing, and distribution.

Hiezer, J., Render, B. (2008). Operations Management (7th ed.). Pearson Prentice Hall, Upper Saddle River, New Jersey.

Hussein, M. (2006). Health services provided to patients admitted in government hospitals in Irbid, Jordan. A study in Geographical Services. Manarah Journal, 13(1).

Imam, W. (2003). The determinants of the quality of health service and its impact on customers' satisfaction in university and private hospitals in Dakahlia Governorate. The Egyptian magazine Commercial Studies, 27(4). )

Khosrov, A. M. K. (2008). Marketing Health Services, a research of Specialist diploma in hospital management. the International Advisory Centre for Management Development, Britain.

Kumar, S. A., \& Sursh, N. (2008). Production and Operations Management ( $2^{\text {nd }}$ ed.). New Age International Limited, Publishers, New Delhi.

Nuseirat, F. T. (2008). Hospital management ( $\left(1^{\text {st }}\right.$ ed.). Esra for Publishing and Distribution, Amman, Jordan.

Philip, K. (1975). Marketing Management-Analysis-Planning and Control. Englow Wood Cliffs -New jersey, Prentice Hill.

Quader, M. (2009). Manger and patient perceptions of a Qoality Outpatient service: Measuring the Gap. Journal of Service Research, $9(1)$.

Saif, M. (2013). The impact of the application of service quality dimensions in patient results. A field study on primary health care centers in Jordan. Jordan Journal of Business Management, 9(4).

Schroeder, R. G. (2007). Operations Management ( $3^{\text {rd }}$ ed.). Mc Grew-Hill Irwin, Boston.

Sultan, W. A. (2013). The dimensions of the quality of health services from the perspective of the beneficiaries .a case study of a group of private hospitals in the province of Basra, Journal of Management and Economic Sciences, 5(10).

Sumaidaie, M. (1999). Introduction to advanced Marketing, Amman- Dar Zahran for printing and publishing and distribution.

Tawil, A., Galilean, A., Hassib, L., \& Riad, J. (2010). The possibility of establishing the quality of health services dimensions. A case Study of group of hospitals in the province of Nineveh Tikrit. Journal of Management and Economic Sciences, 6(9).

Zarei, A., Arab, M., Froushani, A., Rashidian, A., \& Tabatabaei, M. (2012). Service Quality of private hospitals; The Iranian patient perspective. BMC Health Service Research, 12(31). https://doi.org/10.1186/1472-6963-12-31

\section{Copyrights}

Copyright for this article is retained by the author(s), with first publication rights granted to the journal.

This is an open-access article distributed under the terms and conditions of the Creative Commons Attribution license (http://creativecommons.org/licenses/by/4.0/). 